\title{
Quando a Aluna se Torna a Mestre: Um Relato da Experiência de Alunas de Graduação Aplicando Dinâmicas de Ensino de Computação para Alunas de Ensino Médio
}

\author{
Nathasha Pinto ${ }^{1}$, Alana Araujo ${ }^{1}$, Estephane Mendes ${ }^{1}$, Giovanna Pavani ${ }^{1}$, Karla Silva ${ }^{1}$, \\ Raimundo Neto ${ }^{2}$, Katia Salles ${ }^{3}$, Luis Rivero ${ }^{1,2}$ \\ ${ }^{1}$ Programa de Educação Tutorial do curso de Ciência da Computação (PETComp) \\ Universidade Federal do Maranhão (UFMA) - São Luís - MA - Brasil \\ ${ }^{2}$ Programa de Pós-Graduação em Ciência da Computação (PPGCC), \\ Universidade Federal do Maranhão (UFMA) - São Luís, MA - Brasil \\ ${ }^{3}$ Departamento de Tecnologia química \\ Universidade Federal do Maranhão (UFMA) - São Luís, MA - Brasil \\ \{nathashaara, alana.araujo35, estephanemn2203, \\ esteve.giovanna\}@gmail.com, felicia.c@outlook.com, raaneto@gmail.com, \\ katia.salles@ufma.br, luisrivero@nca.ufma.br
}

\begin{abstract}
The number of women in careers and courses in the areas of Computing and Technologies is lower to the number of men. To encourage women to take courses in the field of technology, several extension projects have been carried out. In this context, this paper reports the results of the application of an event in which teaching activities involving computing concepts were carried out. The activities and the prepared material were chosen and adapted by students of the computer science course at the Federal University of Maranhão in order to encourage high school students. As a result of this experience, it was possible to collect opinions about the process of creating the contest by undergraduate students and the evaluation of the contest by high school students.
\end{abstract}

Resumo. O quantitativo de mulheres nas carreiras e cursos das áreas de Computação e Tecnologias é baixo se comparado ao quantitativo de homens. Para incentivá-las a entrar em cursos de exatas, vários projetos de extensão têm sido executados. Nesse contexto, o presente artigo relata os resultados da aplicação de uma gincana em que foram realizadas atividades de ensino envolvendo computação plugada e desplugada. As atividades e o material preparado foram escolhidos e adaptados por alunas do curso de ciência da computação da Universidade Federal do Maranhão com o intuito de encorajar alunas de ensino médio. Como resultado desta experiência, foi possível coletar opiniões sobre o processo de criação da gincana por parte das graduandas e a avaliação da mesma por parte de alunas de ensino médio.

\section{Introdução}

Segundo Maciel e Bim (2017), o número de mulheres atuando em áreas de Tecnologia da Informação (TI) tem diminuído, tornando-se uma preocupação mundial. De acordo com uma 
matéria da Microsoft intitulada "Why don't European girls like science or technology", meninas entre 11 e 15 anos tem interesse por tecnologias e inovações, mas como não são incentivadas ou não possuem muitos modelos femininos na área nos quais se inspirar, acabam migrando para outras áreas. Para Binkerd e Moore (2002), o fato das meninas não serem incentivadas durante a juventude por suas relações sociais ou sua educação traz um efeito negativo quanto à tentativa de incentivo para o papel feminino nas áreas científicas.

Considerando que em muitas escolas públicas, o ensino do pensamento computacional, assim como a falta de infraestrutura para essa educação, ainda não é obrigatório durante a formação dos alunos, as meninas tendem a sentir dificuldades em se relacionar com a área de computação [Neto et al., 2013]. Dessa forma, muitas alunas não sabem da possibilidade de trabalhar na área de computação ou, ao descobrirem, muitas vezes acabam sofrendo um impacto negativo devido aos obstáculos relacionados com a falta de motivação ou falta de conhecimento [Silva et al. 2019].

Visando mudar este cenário, vários programas de incentivo à entrada de meninas nos cursos de computação têm sido criados (ex. Rails Girls, Women Who Code, Sarminina Cientistas, entre outros) [Monard e Fortes 2013]. Motivadas por estas iniciativas, as discentes do Programa de Educação Tutorial, um programa estudantil que visa facilitar a realização de atividades extracurriculares para complementar a formação acadêmica de alunos de ensino superior, do Curso de Ciência da Computação (PETComp) da Universidade Federal do Maranhão (UFMA) decidiram propor uma gincana visando incentivar alunas do ensino médio nesse contexto.

\section{Metodologia}

O projeto executado teve como foco introduzir alguns conceitos básicos de computação, com o objetivo de mostrar o curso de Ciência da Computação para as alunas do Ensino Médio, visando despertar interesse delas na área. Para tal, durante um período de três semanas, as graduandas do grupo PET fizeram uma pesquisa em fontes relacionadas ao ensino de computação para pessoas inexperientes e/ou crianças e adolescentes, incluindo dinâmicas e cursos online. Adicionalmente, as alunas pesquisaram por artigos científicos que relatassem o uso de dinâmicas no ensino de computação para crianças, visando identificar ideias de metodologias que pudessem ser replicadas no contexto da gincana.

Após esta atividade, as alunas do ensino médio realizaram reuniões com o objetivo de definir quais atividades seriam realizadas no período da gincana com duração de 3 a 4 horas, indicando as atividades que seriam realizadas, materiais que seriam necessários para sua execução e público alvo. Nesse contexto, o dia da gincana foi dividido em três momentos que envolveram, atividades desplugadas (dinâmicas sem a necessidade de um computador), um minicurso de Scratch e a apresentação de uma revista em quadrinhos. Tal divisão foi feita pensando no desenvolvimento da lógica computacional e práticas para ajudar na compreensão do assunto, além de mostrar personagens femininos históricos e seus descobrimentos/contribuições nas áreas de exatas e computação.

Para o primeiro momento, foi feita uma apresentação com o objetivo de mostrar o conceito de ciência da computação, os tópicos de computação desplugada e algoritmos. Após a introdução, foram aplicadas duas atividades de computação desplugada que demonstravam conteúdos básicos da área de tecnologia, apresentadas na forma de brincadeiras. As

\footnotetext{
${ }^{1} \mathrm{https}$ ///news.microsoft.com/europe/features/dont-european-girls-like-sciencetechnology/
} 
atividades desplugadas são uma forma de ensinar o pensamento computacional com dinâmicas que ensinam fundamentos da Ciência da Computação sem a utilização de computadores. De acordo com Bell et al. (2007), essas atividades trazem benefícios por serem mais acessíveis e econômicas uma vez que não utilizam de computadores ou outros dispositivos eletrônicos. Estas atividades possuem diferentes objetivos, dentre eles, entender como um computador interpreta entradas de comandos ou como funciona uma lógica de programação básica.

As atividades utilizadas foram retiradas do livro "Computer Science Unplugged" [Bell et al. 2011], sendo levemente adaptadas conforme achou-se necessário. Nesse contexto, as atividades: "Vinte perguntas" e "Contando os pontos" foram as escolhidas para serem aplicadas no projeto. "Vinte perguntas" é um jogo em equipe em que um dos membros escolhe um número qualquer e os outros deverão adivinhar fazendo apenas perguntas que podem ser respondidas com sim ou não. O objetivo do jogo é tentar fazer o menor número de perguntas e acertar o número escolhido, simulando um algoritmo de busca. Por sua vez, "Contando os Pontos" é um jogo aplicado em times que utiliza de cartões com representações de números $(1,2,4,8,16)$ para representar números binários. A atividade tem o objetivo específico de mostrar como os dados são transmitidos em um computador e como ocorre a conversão de números. As meninas foram divididas em equipes e cada equipe teve como finalidade representar números binários usando os cartões confeccionados.

No segundo momento da gincana, foi realizado o minicurso que teve como objetivo abordar os fundamentos de programação no computador. As alunas de graduação decidiram utilizar o Scratch $^{2}$ como ferramenta de programação em blocos, visto que este recurso possibilita um aprendizado mais intuitivo e dinâmico [Aono et al. 2017]. Antes de aplicar a ferramenta, foram explicadas as instruções básicas de decisão e repetição da lógica de programação que seriam utilizados no Scratch. Após tiradas as dúvidas sobre estes conceitos, foi iniciado o minicurso e logo após foi aplicada uma lista de questões em forma de desafios a serem respondidos com lógica de programação em blocos em uma folha de papel.

A última atividade realizada na gincana foi a apresentação da revista em quadrinhos contendo informações sobre mulheres importantes para a área de computação e ciências exatas. Ao todo são seis revistas em estilo Mangá (um estilo de desenhos em quadrinhos de origem japonesa) foram disponibilizadas, contando a história de: Katie Bouman, Evelyn Boyd Granville, Emma Haruka, Margaret Hamilton, entre outras. A forma de apresentar as histórias às meninas foi por meio digital no site do grupo PET de computação para as alunas terem representatividade no meio dos quadrinhos. O projeto foi desenvolvido por meninas para meninas, sendo assim uma forma de mostrar que caso elas decidam seguir nessa carreira, terão o apoio de mulheres dentro do curso.

\section{Resultados e Discussão}

O projeto de extensão do PETComp procura fazer atividades com pessoas externas ao espaço acadêmico da universidade. Consequentemente, duas escolas foram contatadas para participar da gincana. O evento foi aplicado em dois dias, tendo 15 e 22 participantes respectivamente no primeiro e segundo dia de aplicação. No primeiro dia, as participantes pertenciam ao Instituto Estadual de Educação, Ciência e Tecnologia do Maranhão (IEMA) e estavam no primeiro mês do curso técnico de informática. No segundo dia, as alunas pertenciam ao Colégio Militar 2 de Julho, o qual não possui foco na área de computação, mas

\footnotetext{
${ }^{2}$ https://scratch.mit.edu/
} 
participa de pequenos projetos voltados à computação. A Figura 1 apresenta uma foto da aplicação da gincana em cada um dos dias. Ao final das atividades, foi aplicado um questionário coletando dados sobre a percepção das discentes participantes. Das 37 meninas, 30 preencheram o questionário que solicitava informações sobre: dinâmica mais interessante e opinião sobre pontos positivos, negativos e oportunidades de melhoria das atividades.

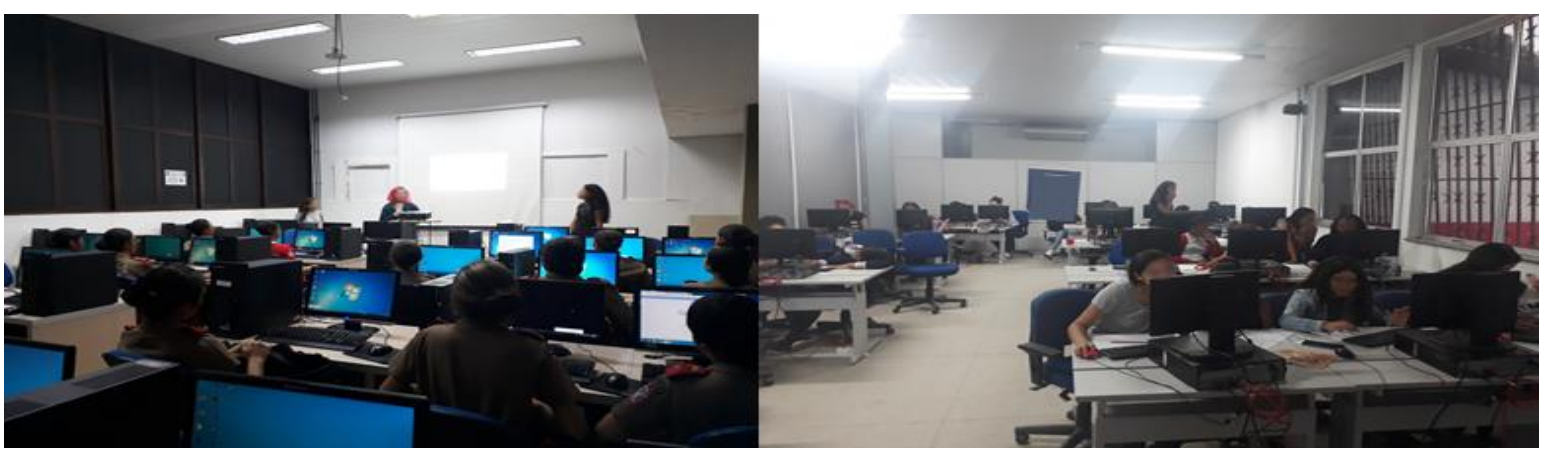

Figura 1 - Apresentação do curso de Scratch para as participantes.

Ao avaliar os resultados do evento foram consideradas as diferenças de uma escola para a outra, devido ao grau de contato das mesmas com o ensino de pensamento computacional. A principal diferença encontrada entre as duas aplicações foi a atenção ao assunto explanado. As participantes da segunda escola conseguiram realizar as tarefas de forma mais rápida que as alunas da primeira escola, devido a estarem mais atentas por ser o primeiro contato delas com projetos relacionados a computação. Outro ponto importante foi a preferência quanto às atividades. Na primeira escola observou-se que as meninas preferiram as atividades desplugadas como o jogo contando os pontos, pois, segundo elas, houve um momento de interação entre elas, e era uma dinâmica bem intuitiva e de fácil compreensão. Já na segunda escola, as meninas preferiram programar com o scratch e entender a parte mais técnica relacionada ao pensamento computacional. A Tabela 1 apresenta o quantitativo de alunas que escolheram cada atividade como atividade preferida, considerando as respostas ao questionário.

Tabela 1 - Preferência das alunas pelas atividades em ambas as escolas

\begin{tabular}{|l|c|c|}
\cline { 2 - 3 } \multicolumn{1}{c|}{} & IEMA & Colégio Militar \\
\hline Atividades Desplugadas & 9 & 4 \\
\hline Atividades Plugadas & 6 & 9 \\
\hline Revista em Quadrinhos & 1 & 1 \\
\hline Total de Alunas & 16 & 14 \\
\hline
\end{tabular}

Entre os motivos para escolher as atividades desplugadas como preferidas, as discentes citaram que facilitava o entendimento de como o computador codificava os dados recebidos usando o sistema binário. A dinâmica das vinte perguntas foi a que obteve menos sucesso, devido ao conhecimento transmitido por essa atividade ser mais difícil de compreender. Por sua vez, o ensino da linguagem scratch nas atividades utilizando o computador, proporcionou o primeiro contato com programação. Segundo as meninas, mesmo sendo programação em blocos, elas conseguiram entender que ações são realizadas através de comandos.

Com relação às revistas, as alunas demonstraram interesse por mais histórias e mais edições das revistas, além de demonstrarem entusiasmo ao ler as histórias. Ao final da 
gincana, algumas delas indicaram no questionário que as atividades despertaram a sua curiosidade e o interesse em ampliar os estudos na área de computação.

\section{Conclusão e Perspectivas Futuras}

Este artigo apresentou a experiência de aplicação do projeto de extensão do Grupo PETComp da UFMA, no contexto de ensino de pensamento computacional para meninas do ensino médio. Ao todo, das 9 alunas participantes da atividade que indicaram não ter conhecimento e/ou ter conhecimento baixo em computação, todas indicaram ter aprendido mais sobre a área e o seu impacto, além de conceitos relacionados a pensamento computacional. Além disso, foi identificado um aumento no interesse das alunas pelo curso de Ciência da Computação, a partir das respostas ao questionário preenchido.

Em futuras aplicações, quanto ao minicurso de Scratch pretende-se aumentar o tempo de aplicação, considerando que algumas meninas que ainda não tinham tido contato com essa ferramenta mostraram ter muita dificuldade em entender as explicações durante a atividade. Para as dinâmicas desplugadas, pretende-se incluir prêmios para as equipes vencedoras como forma de incentivar a participação e aumentar o interesse das discentes em aprender sobre o assunto trabalhado. Com relação à revista, pretende-se adicionar interações com o leitor, guiando a história com base nas ações do mesmo, de modo que o leitor se sinta relacionado com a história. $\mathrm{O}$ grupo de discentes responsável pela dinâmica pretende acompanhar o interesse das participantes desta experiência com o passar do tempo através de questionários e possíveis eventos preparados especificamente para o público feminino. Espera-se que a partir desse relato de experiência, seja possível a aplicação de mais projetos com finalidades similares, envolvendo discentes de graduação no engajamento de alunos de ensino médio com tópicos relacionados ao pensamento computacional em diferentes espaços, incentivando mais discentes, especialmente meninas, a adentrar na área de computação.

\section{Referências}

Aono, A. H., Rody, H. V. S., Musa, D. L., Pereira, V. A., \& Almeida, J. (2017, July). A utilização do scratch como ferramenta no ensino de pensamento computacional para crianças. In Anais do XXV Workshop sobre Educação em Computação. SBC.

Bell, T., Witten, I. H., Fellows, M., Adams, R., \& McKenzie, J. (2011). Ensinando Ciência da Computação sem o uso do computador. Computer Science Unplugged ORG.

Binkerd, C. L., \& Moore, M. D. (2002). Women/minorities in computer science: where are they? no attention no retention. Journal of Computing Sciences in Colleges, 17(5), 8-12.

Maciel, C., \& Bim, S. A. (2017). Programa Meninas Digitais-ações para divulgar a Computação para meninas do ensino médio. Anais do Computer on the Beach, 327-336.

Monard, M. C., \& Fortes, R. P. D. M. (2013). Uma Visão da Participação Feminina nos Cursos de Ciência da Computação no Brasil. In V Congresso de la Mujer Latinoamericana em La Computacion. LAWCC (pp. 6-12). sn.

Neto, J. J. S., De Jesus, G. R., Karino, C. A., \& De Andrade, D. F. (2013). Uma escala para medir a infraestrutura escolar. Estudos em Avaliação Educacional, 24(54), 78-99.

Silva, J., Oliveira, L., \& Silva, A. (2019, July). Meninas na Computação: uma análise inicial da participação das mulheres nos cursos de Sistemas de Informação do estado de Alagoas. In Anais do XXVII Workshop sobre Educação em Computação (pp. 444-452). SBC. 